\title{
Editorial
}

\section{Anyone for teno?}

Musculoskeletal disorders account for an enormous amount of time lost from work by comparison with which that lost from strikes seems almost insignificant. And of all the musculoskeletal disorders, tenosynovitis of the hand and forearm is what one might call a "loss-leader." Indeed, it is now the second commonest prescribed industrial disease in Britain, the most common being dermatitis. So grave does this state of affairs appear to those on the shop floor that one of the largest of the trade unions, the General, Municipal, Boilermakers, and Allied Trades Union, has recently issued a booklet to its members in which the condition is described as an intractable problem that causes long term pain and disability. 'In this respect, the union is following the lead of its Australian counterparts since, in Australia, the disease has in recent years had all the appearances of an epidemic. ${ }^{2}$

As is common in medicine, "new" conditions are often old ones that have been forgotten over the years and tenosynovitis is no exception. It was described before the second world war $^{3}$ and over 35 years ago, Thompson and his colleagues at the Vauxhall Motors Plant described the high incidence in workers engaged in repetitive work in the building of motor cars and trucks. ${ }^{4}$

The true prevalence of the disease is unknown, although it is undoubtedly high in those whose work calls for frequent repetitive movements, and that includes those who work on a moving assembly track to those who sit at the keyboards of word processors. Prevalence rates from $1 \%$ to more than $50 \%$ have been quoted in various studies. ${ }^{5}$

Part of the difficulty in determining how common the disease is lies in distinguishing carefully between the two conditions that are both generally called tenosynovitis. Both conditions are painful, particularly on movement, and both give rise to localised swelling, tenderness, and audible or palpable crepitations. The first of these conditions - what one might call true tenosynovitis - is an inflammation of the synovial lining of the tendon sheath and it is rare but potentially serious. It is confined to the wrist and hand - that is, to those places at which the tendons are to be found. Its treatment generally includes the use of non-steroidal anti-inflammatory drugs (NSAIDS), local injections of steroids, and the application of plaster splints. ${ }^{6}$ Such treatment is usually effective but in some cases surgery must be resorted to in order to release the tendons within their sheath. If surgical treatment is unsuccessful then the patient is likely to become permanently incapacitated and certainly be unable to take up any sort of repetitive work again. ${ }^{2}$

The second type of tenosynovitis is much more common and regarded as much more benign; it is often referred to as peritendinitis crepitans. This is an inflammation at the musculotendinous junction that often also extends well into the body of the affected muscles. The symptoms of this condition are like those of true tenosynovitis but it may readily be differentiated from it by the site of the lesion for unlike tenosynovitis, peritendinitis crepitans does not affect the tendon sheaths and so it is to be found above, and often well above, the site of the tendon sheaths in the muscles of the forearm and at the musculotendinous junctions. Treatment of this condition used formerly to involve immobilisation but this is now no longer considered necessary. It is said that many cases improve spontaneously or in response to treatment with ultrasound and that patients may be able to resume work after four or five days. ${ }^{7}$ I doubt that this is the experience of many occupational physicians; this condition may be extremely difficult to treat, and if the patient returns to the sort of work that brought it about in the first place then it is very likely to recur and to become increasingly severe. A common pattern is for the attacks to remit over a weekend or during a holiday but gradually the pain remains during the period that the patient is away from work unless he or she is away for several weeks. Not a few patients have had to change their work on account of this "benign" condition.

The predominant causes of tenosynovitis of either sort lie in the nature of the work. There are many ergonomic factors ${ }^{89}$ and others due to unsatisfactory work patterns with too little variation and too high a work rate for too long a time ${ }^{2}$; this is particularly so when workers are on piece work rates. Certainly, it is a matter that warrants urgent attention since far too many men and women are having to suffer pain and inconvenience which should be avoided. Our own unpublished studies suggest that almost all those who first take up hard, repetitive work experience pain in the arms and hands within a very short time of starting. This is due to having to use muscles and joints in a way which they have not done before and as soon as they become accustomed to the work these aches and pains tend to disappear. They are followed in many cases, however, by the signs and symptoms of tenosynovitis and one feature to emerge from our work is that many of those with the condition do not 
bring it to medical attention and certainly not to the attention of their managers for fear that they might lose their job. One recent reviewer has taken a somewhat complacent view of the matter, stating that the trade unions are being "alarmist" and that pressure from them might lead to industry being "unfairly penalised with the costs of compensation for minor or even naturally occurring conditions." " One would certainly not wish this to happen, but the view from the vantage point of the occupational physician differs vastly from that of the orthopaedic surgeon and there is no doubt that a substantial proportion of the workforce is afflicted by what is, at best, a painful condition and, at worst, one severe enough to cost the patient his or her job. This is not a minor matter but one that needs much more attention than it is presently receiving. More attention should be given to the design of machinery to reduce the human effort in manufacturing processes; more care should be taken to see that workers carrying out repetitive work have a proper work schedule with reasonable breaks; and the functional component, which is an important feature in some cases, also requires to be carefully researched.

It is surely not to the credit of occupational medicine that a condition that has been known about for so many years is still so common and regarded as a minor nuisance rather than the serious condition it really is.

Editor, British Journal of Industrial Medicine. H A WALDRON

\section{References}

1 General, Municipal, Boilermakers, and Allied Trades Union. Tackling teno. London: College Hill Press, 1986.

2 Browne CD, Nolan BM, Faithful DK. Occupational repetition strain injuries. Guidelines for diagnosis and management. Med J Aust 1984;140:329-32.

3 Howard NJ. Peritendinitis crepitans-a muscle effort syndrome. J Bone Joint Surg [Br] 1937;19:447-59.

4 Thompson AR, Plewes LW, Shaw EG. Peritendinitis crepitans and simple tenosynovitis: a clinical study of 544 cases in industry. $\mathrm{Br}$ J Ind Med 1951;8:150-7.

5 Silverstein BA, Fine LJ, Armstrong TJ. Hand wrist cumulative trauma disorders in industry. Br J Ind Med 1986;43:779-84.

6 Anonymous. Traumatic tenosynovitis of the wrist [Editorial]. $\mathrm{Br}$ Med J 1978;i:528.

7 Evans G. Tenosynovitis in industry: menace or misnomer? $\mathrm{Br} \mathrm{Med}$ $J$ 1987;294:1569-70.

8 Armstrong TJ, Foulke JA, Joseph BS, Goldstein SA. Investigation of cumulative strain disorders in a poultry processing plant. $\mathrm{Am}$ Ind Hyg Assoc J 1982;43:103-16.

9 Luopajarvi T, Kuorinka I, Virolainen M, Holmberg $M$. Prevalence of tenosynovitis and other injuries of the upper extremities in repetitive work. Scand J Work Environ Health 1979;5:48-55.

\section{Correspondence and editorials}

The British Journal of Industrial Medicine welcomes correspondence relating to any of the material appearing in the journal. Results from preliminary or small scale studies may also be published in the correspondence column if this seems appropriate. Letters should be not more than 500 words in length and contain a minimum of references. Tables and figures should be kept to an absolute minimum. Letters are accepted on the understanding that they may be subject to editorial revision and shortening.

The journal now also publishes editorials which are normally specially commissioned. The Editor welcomes suggestions regarding suitable topics; those wishing to submit an editorial, however, should do so only after discussion with the Editor. 